DOI: $10.20472 / E F C .2018 .009 .013$

\author{
JIRI ROTSCHEDL \\ University of Economics, Prague, Czech Republic
}

\title{
ECONOMICS OF OBESITY - CASE STUDIES
}

\begin{abstract}
:
The paper deals with the economics of obesity and consumer decision-making. This paper aims to suggest measures to reduce obesity. The author links economics and some other scientific disciplines, for example, physiology, endocrinology, genetics, etc. Three economic case studies show how all these disciplines play a crucial role in the causes of obesity. Based on the economic case studies, the author suggests the "treatment" of obesity. It includes 1) the tax on unhealthy food (artificial sugar or fructose syrup); 2) sports subsidies or support of sport by public health insurance; and 3 ) restriction on the use of antibiotics. A secondary result of the paper is that individual preferences are not stable due to the changeable set of body and processes inside.
\end{abstract}

\section{Keywords:}

Economic theory, obesity, fructose syrup, Ghrelin, Leptin, economic approach

JEL Classification: D11, I19, L66

This research was supported by Internal Grant Agency IGA F5/2/2018, IGA506018. 


\section{Introduction}

Consumer preferences represent issues on the brink of positive economics and psychology. While a classical economist will stand for the statement that "preferences are stable and do not change," the psychologist will not agree with this view. The approach of the economy is based on focusing on the narrow area of exploring a person using reductionism and deviating from the normative economy. When considering economic theories, we will find that owing to this reduction, in reality; they quite accurately describe the principle of demand generation. For this purpose, the reductionist approach is more than useful.

If we settle for the fact that the reduced models will serve us very well for understanding the principle and will provide us with only limited assistance in modeling the reality, they may be accepted. Today's world, equipped with some technical possibilities, especially in the IT field, does not find these models sufficient. Not only is the artificial intelligence able to reveal the profile of an agent who has just visited your website but even knows his preferences without disclosing them to anyone openly.

IT technology works with agent behavior on the Internet, and with a high degree of accuracy, derives from this behavior who they are, what they may need or what they are looking for on the Internet. At the same time, all the processes take place in the robot and system environment, and the common agent cannot see them.

In order to track or even create demand in practice (owing to the targeted offering of products and services of which the user did not think until the Internet started displaying advertisements through the so-called retargeting), we cannot be assisted by the classical economist. Alternatively, perhaps by a behavioral economist, but we definitely cannot do without psychologists, sociologists and nowadays also geneticists and other scientists from various disciplines.

Psychology and medical discipline are very distant to economists, mainly due to the different methods of work - for instance, exaggerated mathematization and the promoted continuously methodology of the positive economy (Friedman, 1953). Friedman and Samuelson belong to the founders of the positive economy, mathematization, and reductionism in economics. Moreover, it was the mentioned above Samuelson (1948) who separated economy from psychology with his "Revealed Preferences."

While the classical economy has attempted to separate economy from other social sciences since the 1950s, some economists are now seeking a return to mutual co-operation. On the one hand, we are experiencing the era of more powerful IT technologies capable of creating self-learning networks or artificial intelligence and, on the other hand, it has been concluded that conventional economy, due to its reductionist approach, has demonstrated deficiencies in the description of reality, the prediction of consumer behaviour, and the prediction of economic crises.

Supporters of the classical economy often argue with G. S. Becker's claim (1976) that preferences have a stable character in a specific person over time. On the other hand, the same 
economists forget about the addition to this statement, i.e., that "stable preferences do not apply to market goods and services," as expressed by G. S. Becker (1976).

Thus, what is the stability of preferences referred to by G. S. Becker? Stable preferences are based on the physiological settings of the agent, his education or his illnesses (often psychological) and, last but not least, the effects of his surroundings. The following examples serve to demonstrate how these seemingly stable preferences may change over time.

G. S. Becker $(1964,1968,1973,1974,1981)$ turned the role of the economics and applied the economic approach to decision-making on non-economic issues (marriage, criminal activity, etc). In other words, he applied the cost-benefit analysis on decision-making. Unfortunately, he did not continue further and did not investigate the motives of the individuals. He was thus able to explain the circumstances in which marriage or theft paid off, but did not further investigate why some individuals tended to steal while others did not; in other words, why each agent perceives the marginal utility of marriage or theft differently.

It is in particular science disciplines that confirm that the agent perceives marginal utility differently. In other words, some events bring a lower marginal utility than to another one, perceiving a higher utility. Frequently, they are the reason for their physiological/genetic setting; yet education or other soft factors also play an essential role.

It can be demonstrated using the examples of dietary preferences. We will certainly agree that each agent perceives the taste and/or the amount of food differently, i.e., subjectively. Some agents enjoy chips; others prefer vegetable salad, and others meat or some agents will make do with once serving of food, while others need two servings.

The size of the serving which we intend to eat is primarily based by the growth hormone ghrelin, which regulates the appetite or the feeling of hunger (Howard A, Feighner S, Cully D, Arena J, Liberator $\mathrm{P}$, Rosenblum $C$ et al., 1996). Its production in the agent's body may be affected by the genetic mutations in the genes determining the production of this hormone (BAESSLER, $A$. et al. 2004; GUEORGUIEV, M. 2009 et al.).

The opposite effect is produced by the leptin hormone. It forms in the adipose tissue, regulating the feeling of satiety. Obese individuals have been found to have resistance to this hormone (see KLOK, M. D. et al. (2007)), as a result of which its function is impaired. In the case of the obese agent, leptin production after eating food does not induce a sense of satiety, and therefore they tend to overeat. Some studies confirm these findings, e.g., MARTINS, M. do C. (2012).

We are going to introduce fictitious case studies featuring two agents, i.e., the first agent with a higher production of the growth hormone and the other agent with regular production of the growth hormone. Using the economic apparatus, we will demonstrate the following:

- How physiologic predisposition determines the occurrence of obesity;

- Why the spiral of obesity spins owing to the predispositions;

- Why obese people love "all, you can eat" restaurants. 


\section{Case study A - physiology predisposition}

The first agent (AG1) has a stronger appetite (due to the higher production of the ghrelin hormone), the course of his marginal utility with another $100 \mathrm{~g}$ serving of food decreases more slowly than with the second agent (AG2) with the regular production of the ghrelin hormone. A more gradual decline in marginal utility results in the AG1 asking for a higher amount of food than the AG2 at the same price. The gradual decline in the AG1's marginal utility from food also provides us with further information. If the food were free of charge, the AG1 would reach complete satiety at a much higher food dose than the AG2. This situation occurs in the case of children who eat at home and do not have to pay their parents for the meals. The amount of food will, therefore, depend on their satiety point or the slope of the marginal utility curve.

This example can be depicted graphically using the cardinal concept as follows:

\section{Figures 1: Marginal utility of the "overeating" AG1 and the "snacking" AG2}

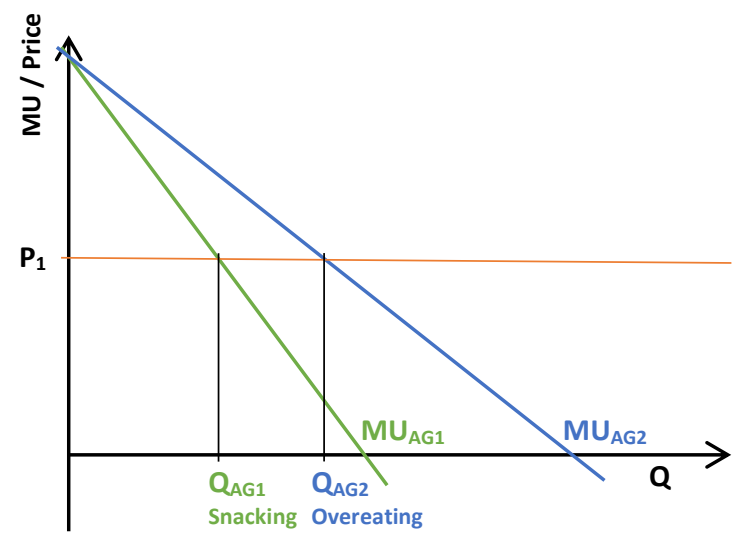

Source: Own layout

Using economic theories, we have managed to explain why some people seek a higher or lower number of goods for the same price. In the case of food, the occurrence of obesity may be explained due to inappropriate genetic predisposition or other factors. Obesity may be induced not only by a higher appetite but also health problems (e.g., thyroid gland malfunction), etc.

The AG1, who has a predisposition to a higher production of the ghrelin hormone, arrives at an increase in fat in the body owing to overeating. The more massive adipose tissue will lead to a higher production of the leptin hormone, to which the body will create resistance. It will result in the consumer changing the marginal utility curve (in other words, changing the basic preferences).

In addition to hormones, preferences may also be changed by some foodstuffs. For instance, the consumption of fructose leads to a decrease in the Leptin level, not resulting in the production of ghrelin (Teff, K. L. et al. 2004; WEISS, R. et al. 2013). For example the agent does not reach the feeling of satiety and drinking beverages sweetened with glucose-fructose syrup (instead of sugar) does not result in suppressing the appetite or the feeling of hunger, and the agent will thus seek additional food units (thus demonstrating a flatter marginal utility curve), which also results in obesity. Preventing the feeling of satiety changes the inclination of the marginal utility curve of food: the agent will reach the complete satiety when consuming a 
higher amount of food, especially in children who do not have to compare the marginal utility of food with its price, thus reaching the state of obesity more easily.

Figure 2: Marginal utility of the growing "overeating" AG1 with the growing level of the leptin hormone

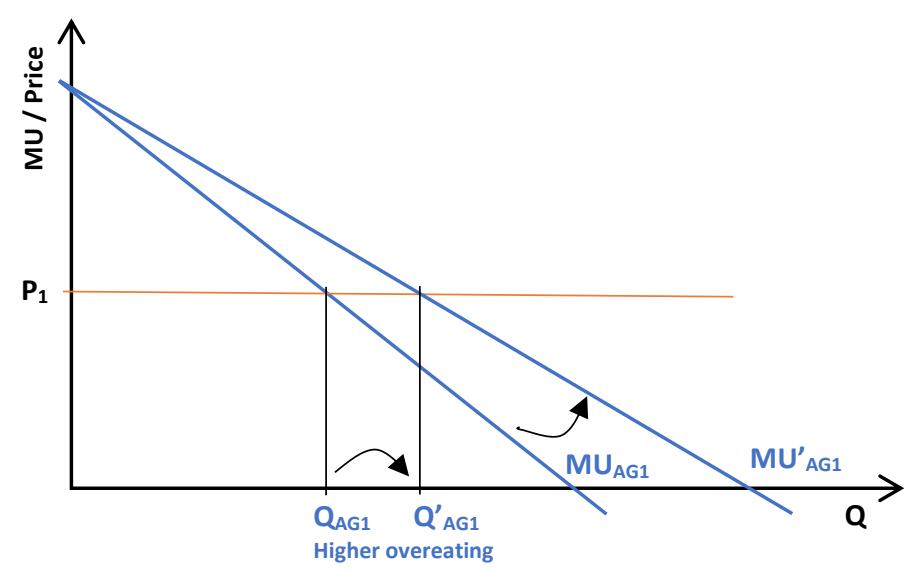

Source: Own layout

The combination of the effects of the ghrelin or leptin hormones causes the spiral of obesity to spin. Excessive food consumption could be labeled as rational, but it is not the case. The perception of satiety is very closely related to the marginal utility on which economic theory is based. The agent maximizes their benefit by demanding the amount of food at which they receive the maximum utility at the specific cost.

The agents ( $A G 2$ ) not suffering from overweight or obesity will label the overeating of the obese agent (AG1) as irrational. This assessment only takes into consideration the AG2's perspective, thus representing the subjective rationality.

\section{Case study B - sport is replaced by food}

If we look at the issue from a perspective of the ordinal theory, we will come to the same conclusions. For instance, we can take the same two agents for whom we expect the same budget. The only two goods which they will purchase are food and sports activities. The AG1, who has an unfavorable predisposition or even consumes fructose very often, has a higher appetite, demonstrating difficulties in reaching the feeling of satiety. For these reasons, he will prefer more food and less sport.

Figure 3 clearly shows that both agents optimize their consumption to the maximum. The AG1 consumes more food, and the AG2 demands more sport. However, limited movement and increased food intake result in obesity acceleration. 


\section{Figures 3: Indifference curve of the AG1 (overeating) and the AG2 (snacking)}

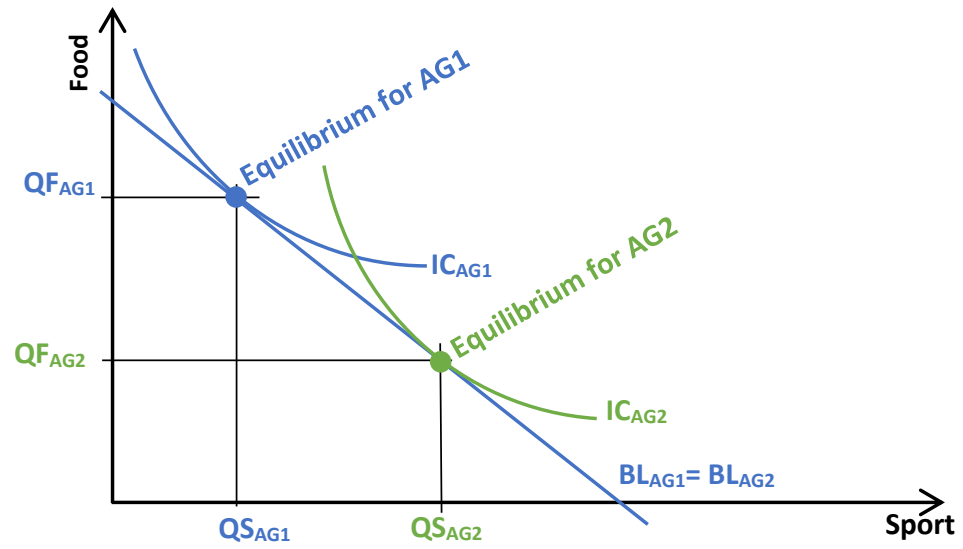

Source: Own layout

\section{Case Study C - "All You Can Eat" Concept}

The third example serves to demonstrate the economic decision-making on the amount of demanded food within the "All You Can Eat" concept.

The amount of food which we consume during unlimited consumption is decided on the one hand by the inclination of the marginal utility curve, but the price itself, or the function of the price of food. For the obese agent with an inappropriate physiological predisposition, the "All you can eat" concept is particularly dangerous mainly due to the gradual decline of its individual marginal utility curve, respectively or the demand which will lead to even greater overeating.

\section{Figures 4: Maximization of Utility - "All You Can Eat" concept}

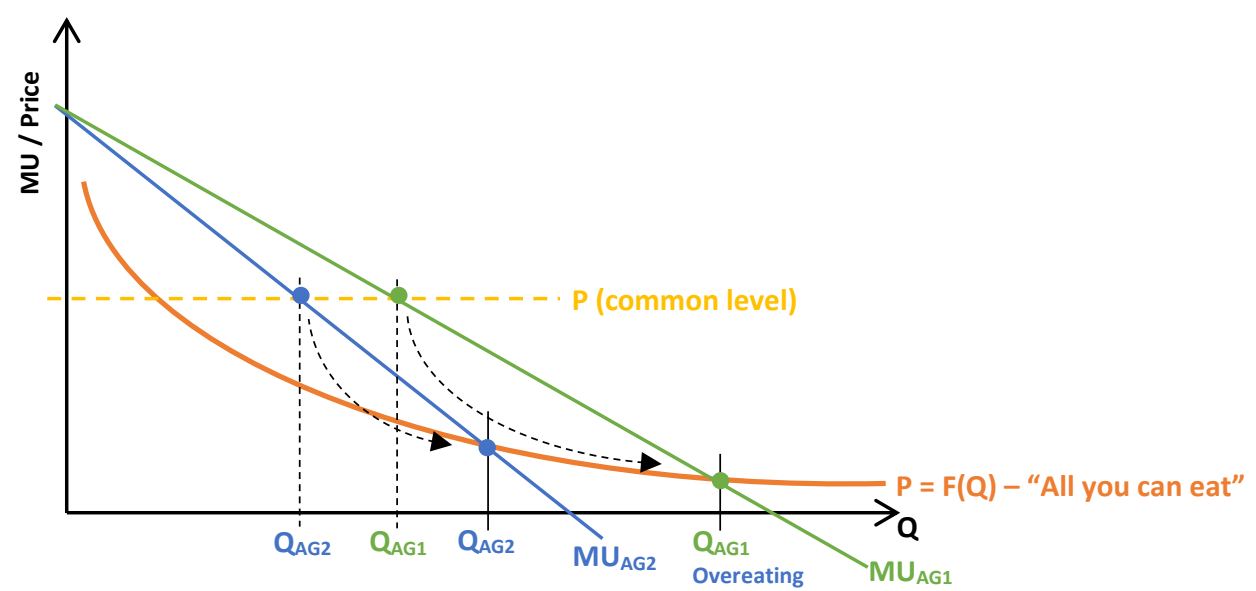

Source: Own layout

The "All you can eat" concept is characterized by a single payment for an unlimited amount of consumed food. Not only the marginal utility but also the average price of the additional food unit decreases with any such additional unit. Apart from the fact that this concept leads to overeating not only in the case of the AG1 but also the originally moderate AG2. The latter will increase the demanded quantity of food only based on the lower average price within the existing marginal utility curves.

Figure 4 shows how the AG1 with an inappropriate physiological predisposition consumes a significantly higher amount of food, as with each additional serving (e.g., $100 \mathrm{~g}$ of food), the 
serving price decreases and the agent is much closer to the full satiety point. It may be stated that in a restaurant with the "All you can eat" concept, the agent reaches higher satisfaction than in a restaurant with a stable average food price.

\section{Discussion}

The economy of obesity and its links with other science disciplines explain how obesity develops and often how difficult it is for rational consumers to fight obesity if they have inappropriate physiological predispositions.

Notwithstanding the already mentioned effects of the hormones on consumer behavior, we may also mention the latest discoveries in the field of natural sciences linking the occurrence of obesity and excessive use of antibiotics. Antibiotics disrupt human microbiome (TILG, H. and KASER A. 2011), the structure of which affects the processing of ingested food. Disrupting the microbiome structure may result in an agent's weight increase, as confirmed by some microbiome studies in relation to obesity, see TILG, H. and KASER A. (2011); ARMOUGOM, F. et al. (2009) or LEY, R. E. et al. (2006). Although this aspect is not related to the actual economy of obesity, it significantly contributes to deepening obesity epidemic problems in advanced economies.

Artificial sweeteners also contribute to obesity, while also representing other health problems (see FOWLER, S.P. (2008)).

\section{Conclusion}

Obesity represents a problem facing the Western world for over fifty years. Recent research has shown that obesity may not only be due to inappropriate foods (fructose syrups, glucosefructose syrups, or artificial sweeteners), but also the overuse of antibiotics over the past 30 years.

The obesity issue can be addressed as a market failure using a state intervention which may, for instance, raise prices of unsuitable food, or adopt measures for stricter prescribing of antibiotics. If we approach the issue only from the positive economics position, then the consumer behavior analysis will not provide any meaningful measures which would contribute to solving the obesity epidemic. However, if we also involve other science disciplines in simple economic models, we will come up with more specific and more effective measures to combat obesity, in particular:

- Imposing consumption tax on unsuitable ingredients (e.g., fructose syrups or artificial sweeteners, etc);

- Preferential pricing of sports activities through more efficient subsidies and support for sports centers or greater motivation of agents through preventive programmes of health insurance companies;

- Determining stricter rules to prevent excessive use of antibiotics.

The proposed measures for the economic policymakers have been confirmed by the economic comparison of the different preferences of the two agents or by mapping the causes of changes in one agent's preferences. With the help of multiple science disciplines, we have arrived at 
practical, though not surprising results and recommendations which may contribute to reducing the obesity epidemic, particularly in the US or other developed countries.

\section{References}

ARMOUGOM, Fabrice, Mireille HENRY, Bernard VIALETTES, Denis RACCAH, Didier RAOULT and Adam J. RATNER. (2009) Monitoring Bacterial Community of Human Gut Microbiota Reveals an Increase in Lactobacillus in Obese Patients and Methanogens in Anorexic Patients. PLoS ONE [online]. 2009, 4(9), e7125- [cit. 2018-0613]. DOI: 10.1371/journal.pone.0007125. ISSN 1932-6203

BAESSLER, A., M. J. HASINOFF, M. FISCHER, et al. (2004) Genetic Linkage and Association of the Growth Hormone Secretagogue Receptor (Ghrelin Receptor) Gene in Human Obesity. Diabetes [online]. 2004, 54(1), 259-267 [cit. 2018-06-12]. DOI: 10.2337/diabetes.54.1.259. ISSN 0012-1797.

BECKER, Gary S. (1964). Human Capital. Chicago: University of Chicago Press, 1964. ISBN 978-0-226-04120-9. S. 412.

BECKER, Gary S. (1968). Crime and punishment: an economic approach. Journal of Political Economy (Chicago Journals) 76 (2): 169-217. DOI: 10.1086/259394

BECKER, Gary S. (1973). A theory of marriage: part I. Journal of Political Economy. 81 (4): 813-846. doi:10.1086/260084

BECKER, Gary S. (1974). A theory of marriage: part II. Journal of Political Economy, special issue: Marriage, Family Human Capital, and Fertility (part 2). 82 (2): p. 11 - p. 26. DOI: 10.1086/260287

BECKER, Gary S. (1976). The economic approach to human behaviour. Chicago: University of Chicago Press, pp. 15-17, ISBN 9780226041124.

BECKER, Gary S. (1981). A Treatise on the Family. Cambridge, MA : Harvard University Press, 1981. ISBN 0-67490698-5.

FOWLER, Sharon P., Ken WILLIAMS, Roy G. RESENDEZ, Kelly J. HUNT, Helen P. HAZUDA a Michael P. STERN. (2008) Fueling the Obesity Epidemic? Artificially Sweetened Beverage Use and Long-term Weight Gain. Obesity [online]. 2008, 16(8), 1894-1900 [cit. 2018-06-13]. DOI: 10.1038/oby.2008.284. ISSN 19307381.

FRIEDMAN, M. (1953). The Methodology of Positive Economics. In: Essays in Positive Economics. Chicago: University of Chicago Press, 1953.

GUeORGUieV, Maria, Cécile LECOEUR, David MEYRE, et al. (2009) Association Studies on Ghrelin and Ghrelin Receptor Gene Polymorphisms With Obesity. Obesity [online]. 2009, 17(4), 745-754 [cit. 2018-06-12]. DOI: 10.1038/oby.2008.589. ISSN 19307381.

HOWARD, A., FEIGHNER, S., CULLY, D., ARENA, J., LIBERATOR, P., ROSENBLUM, et al. (1996). A receptor in pituitary and hypothalamus that functions in growth hormone release. Science 12, 137-145.

KLOK, M. D., S. JAKOBSDOTTIR and M. L. DRENT. (2007) The role of leptin and ghrelin in the regulation of food intake and body weight in humans: a review. Obesity Reviews [online]. 2007, 8(1), 21-34 [cit. 2018-06-12]. DOI: 10.1111/j.1467-789X.2006.00270.x. ISSN 1467-7881.

LEY, Ruth E., Peter J. TURNBAUGH, Samuel KLEIN a Jeffrey I. GORDON. (2006) Microbial ecology: Human gut microbes associated with obesity. Nature [online]. 2006, 444(7122), 1022-1023 [cit. 2018-06-13]. DOI: 10.1038/4441022a. ISSN 0028-0836. 
MARTINS, M. do C., L. LIMA FALEIRO a A. FONSECA. (2012) Relação entre a leptina, a massa corporal e a síndrome metabólica numa amostra da população adulta. Revista Portuguesa de Cardiologia [online]. 2012, 31(11), 711-719 [cit. 2018-06-12]. DOI: 10.1016/j.repc.2012.08.002. ISSN 08702551.

SAMUELSON, P. A. (1948). Consumption Theory in Terms of Revealed Preference. Economica. Vol. 15, No. 60, pp. 243-253.

TEFF, K. L., S. S. ELLIOTT, M. TSCHÖP, et al. (2004) Dietary Fructose Reduces Circulating Insulin and Leptin, Attenuates Postprandial Suppression of Ghrelin, and Increases Triglycerides in Women. The Journal of Clinical Endocrinology \& Metabolism [online]. 2004, 89(6), 2963-2972 [cit. 2018-06-12]. DOI: 10.1210/jc.2003-031855. ISSN 0021-972X.

TILG, H. and Arthur KASER. (2011) Gut microbiome, obesity, and metabolic dysfunction. Journal of Clinical Investigation [online]. 2011, 121(6), 2126-2132 [cit. 2018-06-13]. DOI: 10.1172/JCI58109. ISSN 0021-9738. Dostupné z: http://www.jci.org/articles/view/58109

WEISS, Ram, Andrew A. BREMER a Robert H. LUSTIG. (2013) What is metabolic syndrome, and why are children getting it?. Annals of the New York Academy of Sciences [online]. 2013, 1281(1), 123-140 [cit. 2018-06-12]. DOI: 10.1111/nyas.12030. ISSN 00778923. 